\title{
Mechanical Integrity in Dynamic Interpenetrating Hydrogel Network of Supramolecular Peptide- Polysaccharide Supports Enhanced Chondrogenesis
}

\author{
Jijo Thomas, ${ }^{\dagger}$ Nidhi Gupta, ${ }^{\dagger}$ Jojo P. Joseph, Vianni Chopra, Asish Pal* and Deepa Ghosh*
}

Chemical Biology Unit, Institute of Nano Science and Technology, Knowledge City, Sector 81, Mohali, Punjab 140306 (India).

*Corresponding author. E-mail: apal@inst.ac.in, deepa.ghosh@inst.ac.in

These authors contribute equally

\section{Table of Contents}

1. Persistence Length determination S-2

2. FTIR Spectra S-3

$\begin{array}{ll}\text { 3. Thixotropic studies } & \text { S-4 }\end{array}$

4 Storage modulus of hydrogels after self-healing S-5

5 Comparison of storage modulus S-6

6. Injectability studies $\quad$ S-7

$\begin{array}{ll}\text { 7. Cytocompatibility studies } & \text { S-7 }\end{array}$ 

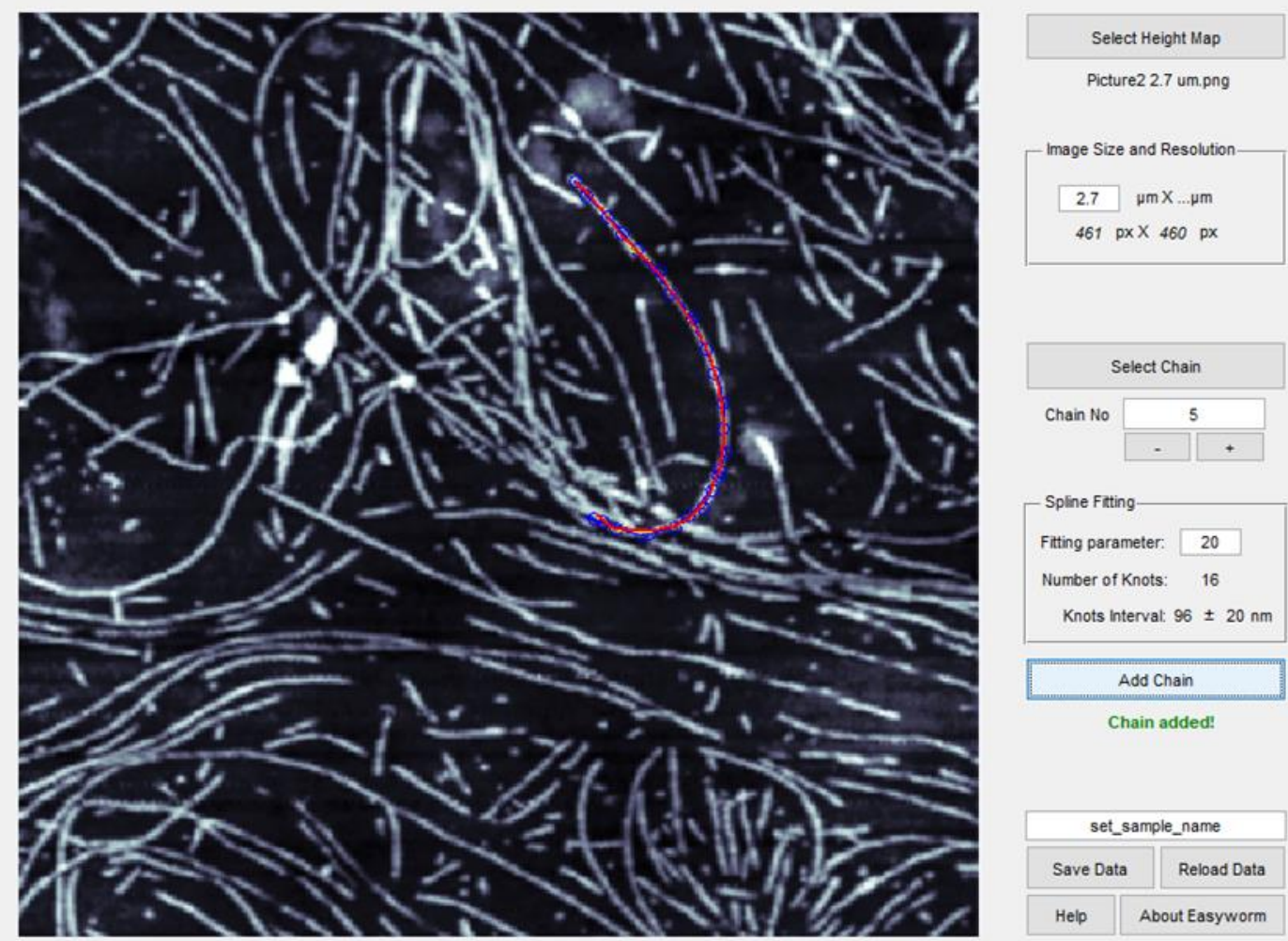

Spline Fitting
Fitting parameter: $\quad 20$
Number of Knots: 16
Knots intervat: $96 \pm 20 \mathrm{~nm}$

Knots Intervat: $96 \pm 20 \mathrm{~nm}$

Add Chain

Chain added!
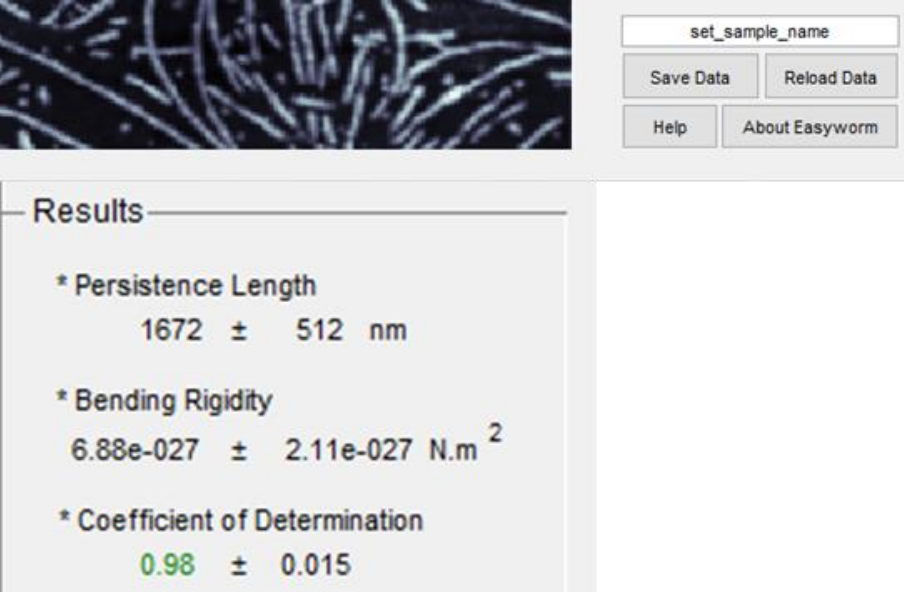

Figure S1. Easyworm GUI fitting of $\mathbf{1}_{\mathbf{N F}}$ to find out the persistence lengths and bending rigidities of the peptide nanostructure. Persistence length was determined to be around $1.6 \mu \mathrm{m}$. 


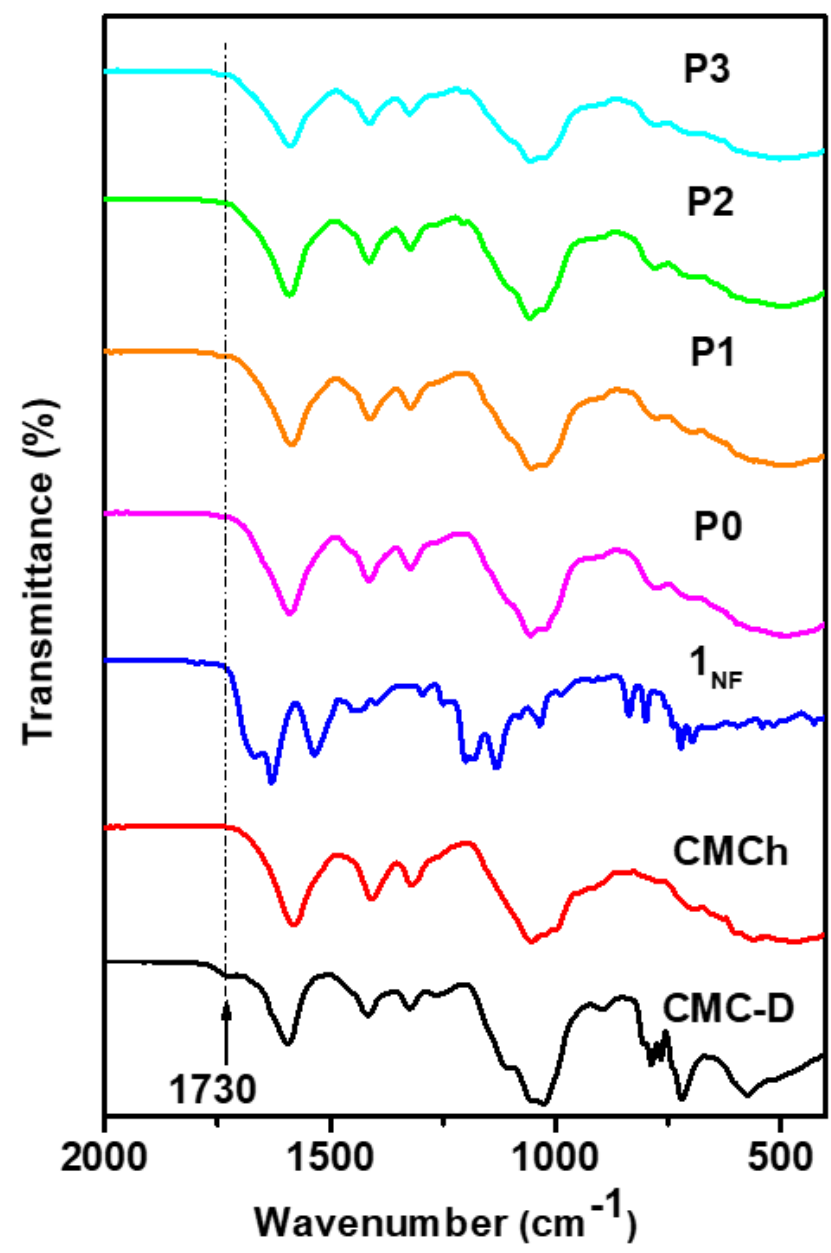

Figure S2. FTIR spectra for different hydrogel samples along with its precursors. Absence of aldehyde band (at $1730 \mathrm{~cm}^{-1}$ ) in the P0, P1, $\mathbf{P 2}$ and $\mathbf{P 3}$ hydrogel spectrum in comparison to carboxymethyl cellulose dialdehyde (CMC-D) confirmed the formation of the imine bond. 

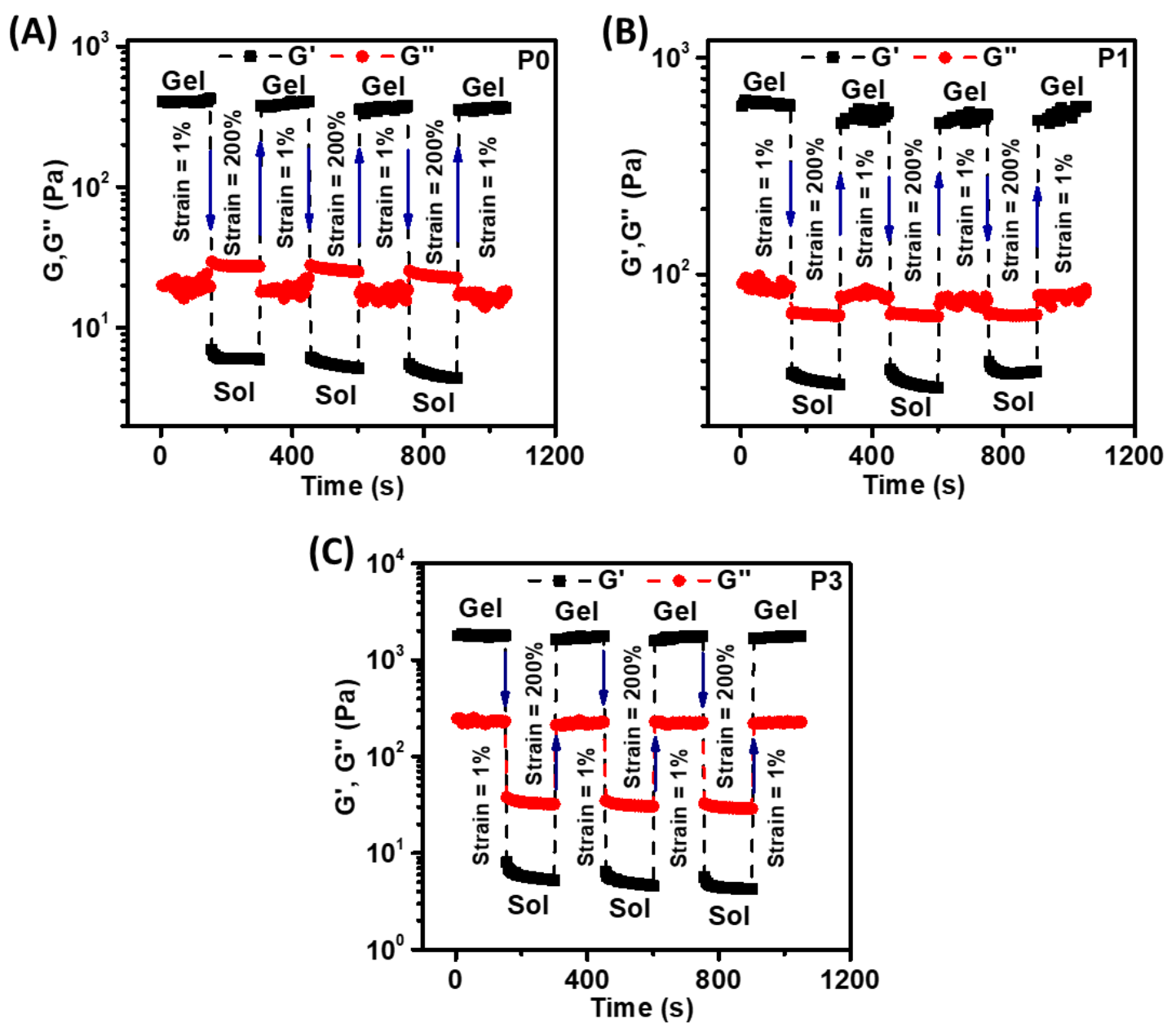

Figure S3. Thixotropic studies for the hydrogel (A) P0, (B) P1 and (C) P3 in PBS buffer upon applying alternative cycle of high $(200 \%)$ and low strains $(1 \%)$ at a constant angular frequency of $10 \mathrm{rad} / \mathrm{s}$. Alternative transition in state from gel-sol-gel subjected to different mechanical strain reflected the injectability nature of the hydrogel. 


\begin{tabular}{|c|c|c|}
\hline Hydrogel composition & $\begin{array}{c}\text { Storage moduli in Pa } \\
\text { (total polymer/peptide content used) }\end{array}$ & Reference \\
\hline $\begin{array}{l}\text { Transglutaminase-crosslinked } \\
\text { hyaluronan }\end{array}$ & $\begin{array}{l}300 \text { to } 2000 \\
\text { (at concentration } 1 \text { to } 3 \% \text { ) }\end{array}$ & $\begin{array}{l}\text { Broguiere } \\
(2016)^{1}\end{array}$ \\
\hline $\begin{array}{l}\text { Adipic dihydrazide-modified PLGA } \\
\text { and aldehyde-modified PLGA }\end{array}$ & $\begin{array}{l}300 \text { to } 1000 \\
\text { (at } 3 \% \text { to } 6 \% \text { ) }\end{array}$ & Yan $(2016)^{2}$ \\
\hline $\begin{array}{l}\text { Aldehyde functionalised hyaluronic } \\
\text { acid, hydrazide- functionalized } \gamma \text { - } \\
\text { PGA and methacrylate- } \\
\text { functionalized } \gamma \text {-PGA ( } \gamma \text {-PGAGMA) }\end{array}$ & $\begin{array}{c}250-500 \\
\text { (at } 10 \%-40 \% \text { ) }\end{array}$ & Ma $(2020)^{3}$ \\
\hline $\begin{array}{c}\text { Hyperbranched poly(ethylene glycol) } \\
\text { and thiol functionalised hyaluronic } \\
\text { acid }\end{array}$ & $\begin{array}{c}600-1000 \\
\text { (at } 2.5 \text { to } 10 \% \text { ) }\end{array}$ & $\mathrm{Li}(2020)^{4}$ \\
\hline Hyaluronic acid alginate hybrid & $400-1100$ (at $2 \%$ with different M.W.) & Lee $(2020)^{5}$ \\
\hline Hydroxypropyl chitin & $\sim 300($ at $3 \%)$ & $\mathrm{Xu}(2020)^{6}$ \\
\hline $\begin{array}{l}\text { Collagen type I-tyramine conjugate } \\
\text { and hyaluronic acid-tyramine } \\
\text { conjugate }\end{array}$ & $\sim 700$ (at 5\%) & Zhang $(2020)^{7}$ \\
\hline $\begin{array}{l}\text { Hyaluronic acid-SH /peptide (BPAA- } \\
\text { AFF-OH) hybrid }\end{array}$ & $\sim 600(3 \%)$ & Wang $(2020)^{8}$ \\
\hline $\begin{array}{c}\text { CMC-D, CMCh \& } 1_{\mathrm{NF}} \\
(\mathrm{P} 1, \mathrm{P} 2 \& \text { P3) }\end{array}$ & $\begin{array}{c}\sim 300-3000 \\
(\text { at } 2.01-2.2 \%)\end{array}$ & Present Work \\
\hline
\end{tabular}

Table S1. Comparison of storage modulus of some of the relevant injectable hydrogels reported for chondrocyte delivery against the developed double network hydrogel. 


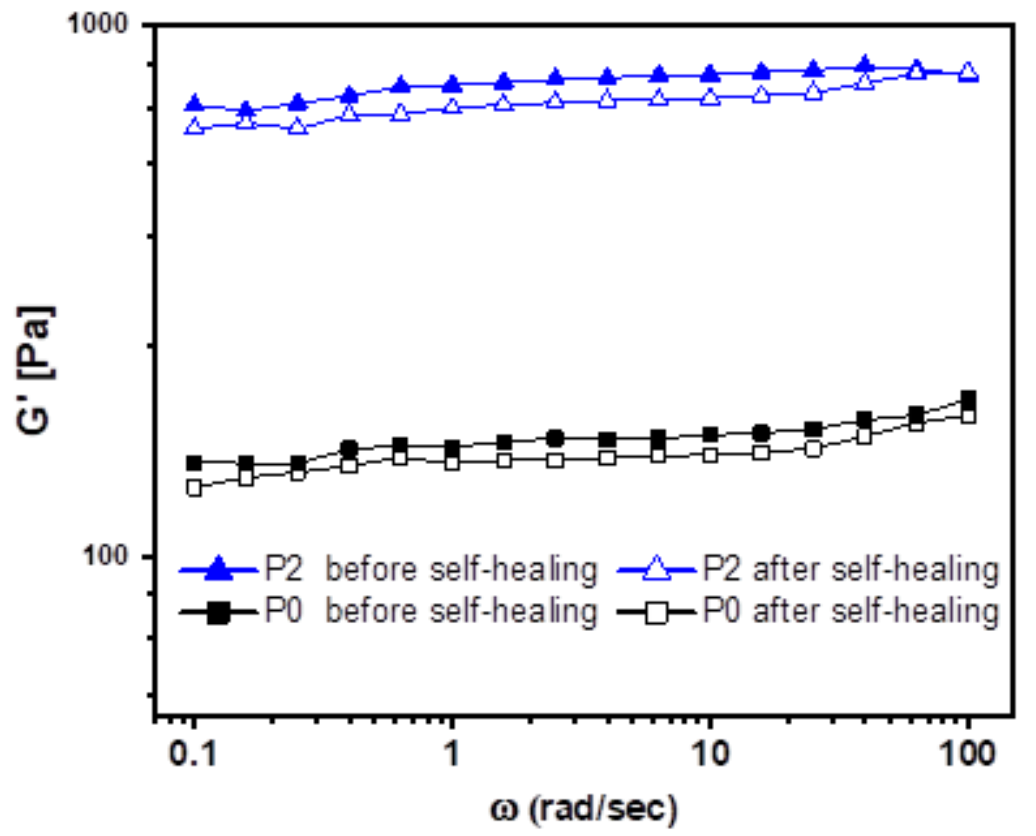

Figure S4. Comparison of storage moduli before and after the self-healing process for $\mathbf{P 0}$ and $\mathbf{P 2}$ hydrogels. The storage modulus of the hydrogels were recorded using frequency sweep oscialltaory rheology.

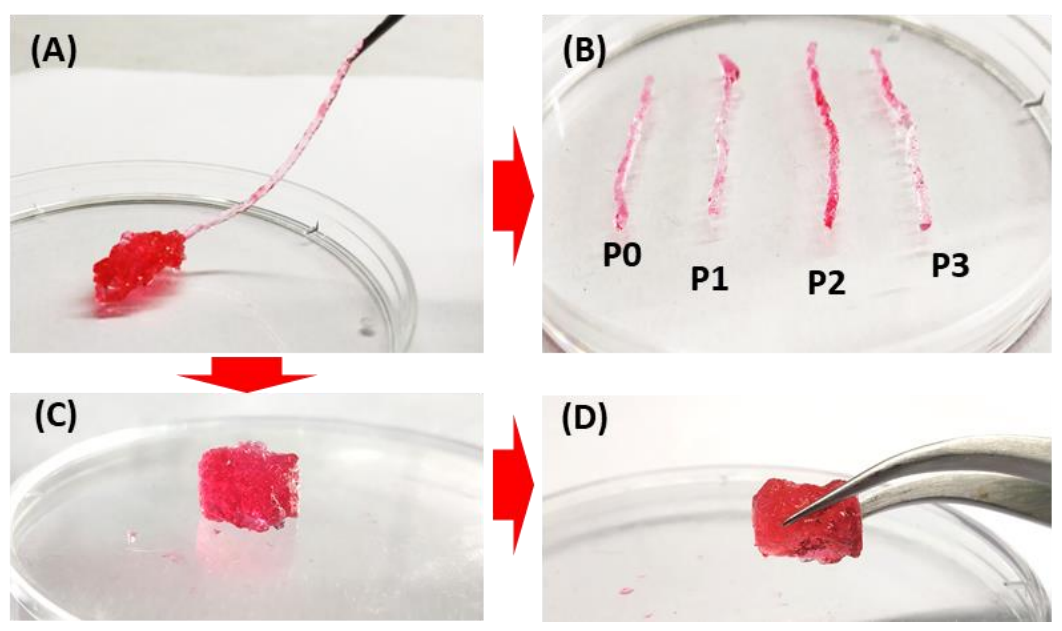

Figure S5. Injectability of the hydrogels of P0, P1 P2 and P3. (A) The hydrogels were injected through an 18G needle. (B) Hydrogels after post-injection appeared to be in a continuous thread-like shape. (C) Hydrogels after injection were able to reform as a whole block when kept in contact, which can be picked up (D) and stretched as a whole without any distortion. 


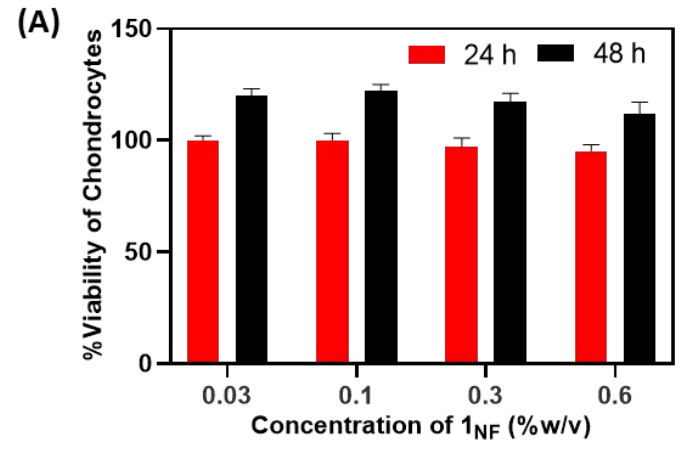

(c)
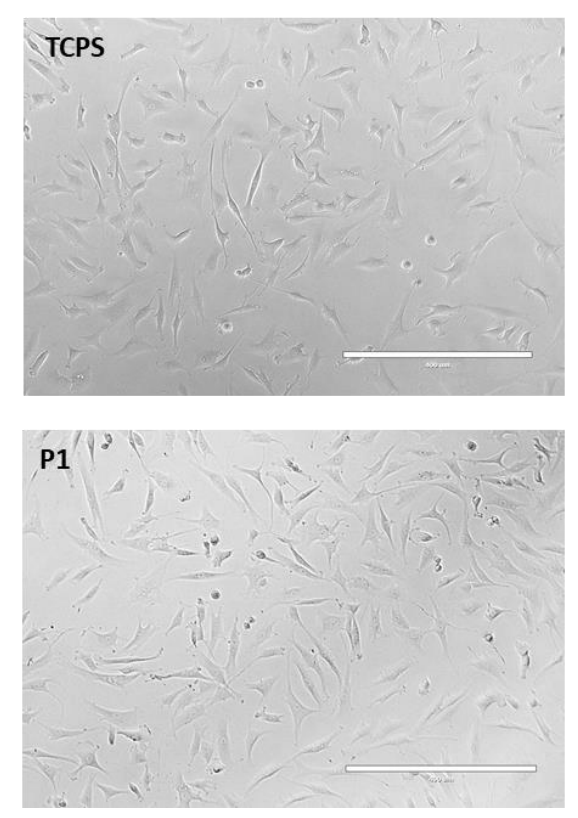

(B)
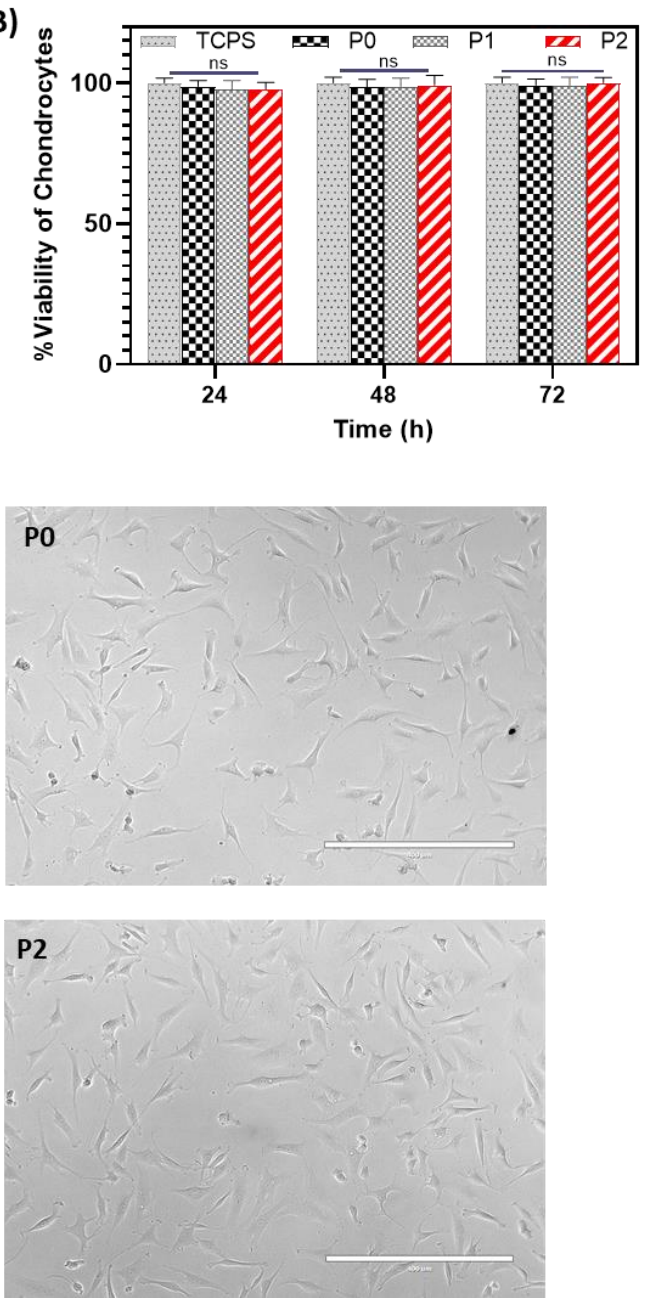

Figure S6. Cytocompatibility of $\mathbf{1}_{\mathrm{NF}}$ and hydrogels. (A) Percentage viability of chondrocytes $v$ s. concentration of 1NF. (B) Cytocompatibility of $\mathbf{P 0}, \mathbf{P 1}$ and $\mathbf{P 2}$ performed using elution media in comparison to the tissue culture polystyrene plate (TCPS). ns indicates no significant change (Two-way ANOVA, Tukey's multiple comparisons test). (C) Microscopic images of chondrocytes displaying the cell morphology after $24 \mathrm{~h}$ treatment. Scale bar 400 $\mu \mathrm{m}$. 


\section{References}

1. Broguiere, N.; Cavalli, E.; Salzmann, G.M.; Applegate, L.A.; Wong, M.Z. Factor XIII Cross-Linked Hyaluronan Hydrogels for Cartilage Tissue Engineering. ACS Biomater. Sci. Eng. 2016, 2, 2176-2184.

2. Yan, S.; Zhang, X.; Zhang, K.; Di, H.; Feng, L.; Li, G.; Fang, J.; Cui, L.; Chen, X.; Yin, J. Injectable in situ forming poly(l-glutamic acid) hydrogels for cartilage tissue engineering. J. Mater. Chem. B 2016, 4, 947-961.

3. Ma, X.; Liu, X.; Wang, P.; Wang, X.; Yang, R.; Liu, S.; Ye, Z.; Chi, B. Covalently Adaptable Hydrogel Based on Hyaluronic Acid and Poly( $\gamma$-glutamic acid) for Potential Load-Bearing Tissue Engineering. ACS Appl. Bio Mater. 2020, 3, 4036-4043.

4. Li, X.; Sigen, A.; Xu, Q.; Alshehri, F.; Zeng, M.; Zhou, D.; Li, J.; Zhou, G.; Wang, W. CartilageDerived Progenitor Cell-Laden Injectable Hydrogel—An Approach for Cartilage Tissue Regeneration. ACS Appl. Bio Mater. 2020, 3, 4756-4765.

5. Lee, H.J.; Seo, Y.; Kim, H.S.; Lee, J.W.; Lee, K.Y. Regulation of the Viscoelastic Properties of Hyaluronate-Alginate Hybrid Hydrogel as an Injectable for Chondrocyte Delivery. ACS Omega 2020, $5,15567-15575$.

6. Xu, Y.; Xu, Y.; Bi, B.; Hou, M.; Yao,L.; Du, Q.; He, A.; Liu, Y.; Miao, C.; Liang, X.; Jiang,X.; Zhou, G.; Cao, Y. A moldable thermosensitive hydroxypropyl chitin hydrogel for 3D cartilage regeneration in vitro and in vivo. Acta Biomater. 2020, 108, 87-96.

7. Zhang, Y.; Cao, Y.; Zhao, H.; Zhang, L.; Ni, T.; Liu, Y.; An, Z.; Liu, M.; Pei, R. An injectable BMSC-laden enzyme-catalyzed crosslinking collagen-hyaluronic acid hydrogel for cartilage repair and regeneration. J. Mater. Chem. B 2020,8, 4237-4244.

8. Wang, Q.; Li, X.; Wang, P.; Yao, Y.; Xu, Y.; Chen, Y.; Sun, Y.; Jiang, Q.; Fan, Y.; Zhang X. Bionic composite hydrogel with a hybrid covalent/noncovalent network promoting phenotypic maintenance of hyaline cartilage. J. Mater. Chem. B 2020, 8, 4402-4411. 